\title{
PERSPECTIVAS
}

Artigo convidado

DOI: http://dx.doi.org/10.1590/So034-759020170410

\section{PERIÓDICOS BRASILEIROS EM INGLÊS: A MÍMICA DO PUBLISH OR PERISH "GLOBAL"}

RAFAEL ALCADIPANI

rafael.alcadipani@fgv.br Professor da Fundação Getulio Vargas, Escola de Administração de Empresas de São Paulo - São Paulo - SP, Brasil
Em dezembro de 2004, foi publicado o primeiro periódico acadêmico brasileiro em Administração que recebe artigos somente no idioma inglês. Em seu primeiro editorial, o editor da Brazilian Administrative Review $(B A R)$ argumenta que o periódico surgira com o intuito de expandir a produção científica em Administração do Brasil para uma audiência mais ampla, que possuía o inglês como língua dominante. 0 editorial, ainda, destacava que o novo journal não se restringiria a publicar artigos de brasileiros em inglês. Ele também pretendia ser um veículo para que autores de outros países publicassem seus textos para uma audiência brasileira.

Recentemente, a Revista de Administração da Universidade de São Paulo (RAUSP), periódico com 70 anos de história e um dos principais construtores do campo acadêmico da Administração no Brasil, passou a publicar os seus artigos somente em inglês. Para tanto, argumentou, em seu editorial publicado em janeiro de 2016, que "a crescente globalização do ensino e pesquisa de Administração e Contabilidade quer a exposição da produções e manutenção do diálogo com esta comunidade global e, para isso, o idioma não pode ser uma barreira". O Scientific Electronic Library Online (SciELO), principal indexador de periódicos do Brasil, exige que todas as revistas científicas que fazem parte de sua base tenham, cada vez mais, textos publicados em inglês. Desde 2008, a Fundação Getulio Vargas, Escola de Administração de Empresas (FGV EAESP), publica o Journal of Operations and Supply Chain Management (JOSCM), periódico exclusivamente publicado em inglês, e há diretivas no sentido de que todos os periódicos científicos editados pela FGV gradualmente contenham um número crescente de artigos em inglês. No ano de 2015, a RAE-Revista de Administração de Empresas publicou mais artigos em inglês do que em português, fato destacado pelo editor no número 6 do volume 55. Em outros periódicos, como a Revista Brasileira de Gestão de Negócios (RBGN), nos últimos anos, publicam-se edições com artigos em duas línguas, sendo uma delas necessariamente o inglês. Boa parte dos periódicos bilíngues ou publicados somente em inglês é tida como de prestígio no Brasil.

Tais dados mostram que há um crescente número de periódicos acadêmicos publicados no Brasil que são ou publicados majoritariamente em inglês ou exigem que ao menos uma das versões do artigo seja em inglês. Neste ensaio, eu problematizarei a crescente utilização do inglês como idioma para artigos acadêmicos publicados no Brasil, discutindo a necessidade de articularmos uma resistência ao mundo acadêmico do publish or perish. 


\section{ACADEMIA BRASILEIRA DE ADMINISTRAÇÃO COMO MÍMICA DO PUBLISH OR PERISH ANGLO-SAXÃO}

A RAUSP é publicada desde 1947, embora sua publicação tenha sido interrompida entre 1967 e 1977. A RAE é publicada desde 1961, e a RAP-Revista de Administração Pública existe desde 1967. Em comparação, o principal polo de produção e disseminação do conhecimento na nossa área no mundo, a Administrative Science Quarterly, um dos mais antigos periódicos de Administração nos Estados Unidos, é publicada desde 1956. Ou seja, periódicos brasileiros na área de gestão existem há tanto tempo quanto nos EUA. Todavia, a lógica da produção científica nos dois países seguiu caminhos diferentes ao longo dos anos.

No mundo anglo-saxão, a produção científica e, consequentemente, os periódicos acadêmicos estão imersos na lógica do publish or perish (anglo-saxão), que está relacionado com o pragmatismo para escrever e publicar (Wilson, 1942). Tal lógica se consubstancia em uma pressão presente no meio acadêmico para que seus membros realizem publicações de maneira rápida e contínua, geralmente em periódicos, para que os acadêmicos consigam uma posição em uma instituição de pesquisa e mantenham a sua carreira.

Na prática, essa lógica configura-se em um sistema de produção onde artigos publicados em periódicos científicos servem como moeda fundamental para os acadêmicos garantirem a sua atratividade no mercado de trabalho "global" e até mesmo a possibilidade de terem estabilidade no seu emprego (tenure). Se não sobram críticas às consequências desse modelo e seus impactos deletérios na capacidade de inovação e reflexividade do meio acadêmico, bem como nos efeitos que esse sistema causa nas pessoas (Bristow, Robinson, \& Ratle, 2017; Davies, 2015), o sistema "global" dos periódicos anglo-saxões tem incentivado que os acadêmicos produzam em periódicos de alto impacto que tendem a zelar pelo "rigor" daquilo que é publicado.

A empregabilidade do acadêmico no mundo anglo-saxão depende de onde o professor publica os seus artigos. Quanto maior o ranking do periódico onde o pesquisador publica, maior prestígio o acadêmico terá em sua comunidade e maior será a sua chance de conseguir uma posição em uma instituição de excelência ou ao menos de destaque. Instituições de ponta nos EUA e na Europa tendem a contratar acadêmicos que demonstram potencial de publicar em periódicos top que, na grande maioria das áreas, não passam de cinco títulos em áreas específicas do campo. Tais periódicos fazem parte da lista do UT-Dallas Bussiness School Research Rankings. Algumas business schools utilizam os journals que contam para o ranking do Financial Times e outras desenvolvem as suas próprias listas de quais periódicos são importantes. 0 tão sonhado tenure só é concedido após o professor provar que é capaz de publicar cerca de meia dezena de artigos nesses poucos periódicos considerados de prestígio em um espaço de cinco anos. Os artigos tendem a passar por um detalhado processo de avaliação. Vale frisar que todo o sistema de incentivos é feito para que os pesquisadores consigam publicar nesses periódicos. Salários são comparativamente altos, os professores possuem uma carga de aula reduzida, significativamente menor do que as praticadas no Brasil, e um número muito menor de orientandos de doutorado.

Se considerarmos que a produção científica é a consequência das práticas cotidianas socialmente localizadas de acadêmicos (Latour \& Wolgar, 1986) e que práticas e ideias geradas nos países tidos como centrais tendem a assumir novos significados nos países periféricos (Bhabha, 1994), é interessante indagar o que aconteceu com a lógica do publish or perish anglo-saxão quando transladada para a academia brasileira em Administração.

Análises mostram que o campo acadêmico da Administração no Brasil está operando sob a égide do produtivismo (Alcadipani, 2011; Godoi \& Xavier, 2012; Machado \& Biachetti, 2011). Produtivismo acadêmico é "uma ênfase exacerbada na produção de uma grande quantidade de algo que possui pouca substância, o foco em se fazer o máximo de uma coisa 'enlatada', com pouco conteúdo e consequente valorização da quantidade como se fosse qualidade" (Alcadipani, 2011, p. 1174).

Não raro, no Brasil, professores produzem dezenas de artigos anualmente, majoritariamente realizados em coautoria com alunos e publicados em periódicos de baixa circulação. Escassos são os professores que escrevem sozinhos ou em parceria com os seus colegas, ou, ainda, que são primeiros autores da maioria dos artigos que assinam. Pegino (2014) mostra como tais características de produção científica também estão presentes de maneira marcante no grupo de pesquisadores que possuem a bolsa produtividade em pesquisa do Conselho Nacional de Pesquisa (CNPq), considerado o grupo de elite dos acadêmicos nacionais (para detalhes, veja Pegino, 2014).

No Brasil, a qualidade da produção científica do professor não está fundamentalmente atrelada nem à sua empregabilidade nem ao seu prestígio no campo. A maioria dos professores pesquisadores possui sua empregabilidade garantida após um breve período de probatório nas universidades públicas. Para ser aprovado no probatório, não é necessário publicar em periódicos de destaque, como acontece nos EUA. A publicação científica 
impacta a decisão de quem faz ou não parte dos programas de pós-graduação stricto sensu. Tal definição, em geral, passa pela quantidade de pontos que a produção científica do professor aufere, medida pela qualificação do periódico no Qualis da Coordenação de Aperfeiçoamento de Pessoal de Nível Superior (CAPES), a lista que determina a avaliação dos periódicos para os acadêmicos que publicam no Brasil. Na grande maioria das universidades privadas, os professores não possuem estabilidade no emprego, não há tenure, e, com isso, são obrigados aceitar os ditames de seus superiores e vivem em condições de trabalho precárias em comparação ao mundo "global”. A qualificação da sua produção científica é apenas um dos critérios para a sua empregabilidade. Outros incentivos para que os professores publiquem em periódicos de destaque não estão presentes no sistema. O que parece contar mesmo para avaliações de Bolsistas Produtividade no CNPq, e que também contou, até muito recentemente, na avaliação dos programas de pós-graduação realizada pela CAPES, é essencialmente a quantidade da produção científica sem nenhuma preocupação com a qualidade da pesquisa ou do artigo.

Outro fator importante na regulação da produção científica brasileira é a lista do Qualis-Periódicos da CAPES. O Qualis da área de Administração é questionável. Sob o argumento de que pesquisadores realizam pesquisas multidisciplinares no campo da Administração, o Qualis tem aceitado como periódicos de Administração aqueles que flagrantemente nada têm a ver com a área. Periódicos de medicina, odontologia e engenharia de alimentos, somente para citar algumas áreas, aparecem nos estratos superiores da lista. Não vemos, nas áreas de ciências médicas e engenharia, periódicos de Administração nos estratos superiores. O segundo problema é a valorização exacerbada dos periódicos internacionais pouco reconhecidos no exterior. Diferente de áreas como antropologia e sociologia, que possuem periódicos nacionais no estrato $A_{1}$, a área de Administração privilegia critérios de avaliação de periódicos tais como indexadores e outras métricas extremamente burocráticas, o que faz com que os periódicos nacionais sempre estejam em desvantagem. Um problema correlato é que, em nome da “neutralidade", são aplicados critérios para a classificação de periódicos que terminam por desvalorizar sobremaneira a própria área. Falta uma discussão substantiva a respeito dos rumos que deve tomar a pesquisa em Administração no Brasil.

Se seguirmos a já deletéria lógica do publish or perish, percebemos que os principais reguladores do campo acadêmico da Administração no Brasil incentivam a produção de uma grande quantidade de artigos acadêmicos em periódicos de baixa circulação e baixo prestígio, tanto nacional quanto internacional. No que diz respeito à publicação internacional dos brasileiros, ela é ainda muito incipiente e dominada por um gaming expressivo. Parte dos acadêmicos nacionais que procuram publicar em periódicos fora do Brasil o faz nos que são de menor prestígio na área e, portanto, mais fáceis de se conseguir uma publicação em inglês. 0 que parece contar não é a aprendizagem no processo de avaliação e o desenvolvimento acadêmico, mas, sim, ter um artigo em inglês para mostrar no CV. O gaming também explica a grande presença de periódicos internacionais fora da área de Administração. Lembro que problemas como a diferença de lógica de produção científica, de linguagem e de condições materiais de trabalho, tais como alta carga horária em sala de aula e em trabalhos administrativos que nada têm a ver com pesquisa, a necessidade de o professor ter "bicos" para poder ter uma remuneração adequada, entre outros fatores práticos, colocam o acadêmico brasileiro que trabalha em uma instituição do Brasil em clara desvantagem em relação aos seus colegas anglo-saxões.

Considerando a quantidade de acadêmicos na área no Brasil, a quantidade de periódicos editados em português - hoje são cerca de 250 periódicos com foco em Administração no País (SCI\&ORG - Ciência e Organizações, 2017) - e a ausência de relação direta entre produção científica e empregabilidade, o Brasil teria a possibilidade de desenvolver um sistema alternativo ao publish or perish presente no mundo anglo-saxão.

Todavia, nossas instituições acadêmicas terminaram por criar um sistema tão permissivo quanto o reinante fora do Brasil. Isso porque o que caracteriza o publish or perish nacional é o produtivismo acadêmico e o gaming da publicação internacional. Ou seja, o trabalho de produção científica parece ter perdido o significado de construir contribuições acadêmicas consistentes. Parte dos professores está gerindo "fábricas de papers" onde quem realmente faz a pesquisa e escreve os artigos são os alunos. Raramente trabalhos de fôlego e profundidade são produzidos. As reflexões presentes nos artigos são breves, de pouca densidade, de baixa contribuição científica e social e baixo rigor metodológico. É isso o que têm apontado as avaliações a respeito da publicação acadêmica na área de Administração no Brasil (Bertero \& Caldas, 2005; Bertero, Caldas, \& Wood, 1999). Raros são os professores brasileiros que estão baseados no Brasil e publicam em "periódicos internacionais respeitados". Ao fim e ao cabo, elaboramos um simulacro de produção acadêmica anglo-saxã que nem nos posiciona nas discussões acadêmicas “globais" nem nos faz criar um pensamento original e uma prática acadêmica que gere significado efetivo. Bhabha (1994) chama de mímica (mimicry) essa tentativa das pessoas dos países do Sul de copiar as lógicas de funcionamento dos países do Norte sem ter a mesma base social, cultural e econômica. Ao fazer isso, como estamos vendo na academia de Administração no 
Brasil, produzimos uma cópia malfeita que não traz benefícios para nós mesmos.

Diante da lógica de produção científica que impera no Brasil no momento no campo da Administração, qual seria, então, a consequência de termos periódicos editados no Brasil e publicados em inglês?

\section{POSSÍVEIS FACES DOS PERIÓDICOS ACADÊMICOS BRASILEIROS EM INGLÊS: PROVINCIANISMO GLOBAL E COLONIALISMO EPISTÊMICO}

Neste texto, eu utilizo o termo "global" para me referir a um meio acadêmico formado por pessoas e instituições que trabalham dentro da lógica do publish or perish anglo-saxão. Nesse meio científico, o inglês acadêmico norte-americano ou britânico é a língua utilizada como idioma "global" (Altbach, 2007). Outras versões de inglês, como o praticado por indianos, nigerianos e bengalis, por exemplo, não são toleradas. Os periódicos que fazem parte desse campo "global” de pesquisa em Administração possuem uma visão bastante restrita a respeito do que é boa pesquisa acadêmica (comumente funcionalista), do que são artigos científicos de qualidade (em geral, os que são publicados nos journals de prestígio) e daquilo que realmente deve ser publicado (via de regra, pesquisa quantitativa ou qualitativa de uma tradição epistemológica positivista). Assim, possuem uma visão bastante limitada do que é conhecimento científico e tentam transladar isso para outros países do mundo (Bell, Kothiyal, \& Willmott, 2016).

Conforme destaca Ibarra-Colado (2006), esse campo "global" é composto por escolas de negócios consideradas de elite, mega-editoras multinacionais, associações acadêmicas como a Academy of Management, congressos e eventos científicos que se consideram internacionais, muito embora quem esteja ocupando as posições de poder nesses lugares venha de pouquíssimas universidades. Fazem parte ainda desse cenário "global” diversos tipos de rankings para periódicos, cursos e escolas que tendem a indicar quem possui "qualidade". Trata-se de uma verdadeira indústria que trabalha sob a égide da lógica acadêmica como praticada nas escolas de destaque dos países anglo-saxões. Murphy e Zhu (2012) mostram como essa lógica opera nos periódicos acadêmicos que pertencem ao tal mundo "global".

A única forma de ser respeitado nesse circuito "global” é estar presente, apresentando artigos nesses congressos, mas fundamentalmente publicando nos periódicos "globais" e fazendo cursos de formação ou estágios pós-doutorais nas instituições "globais". Essa lógica "global” é bastante provinciana, pois trata como subalternas outras culturas, outros saberes e outras lógicas de se produzir conhecimento. Se você não faz parte desse circuito jet-set internacional, você simplesmente não existe para esse mundo "global". Trata-se de uma variação acadêmica da distinção local/global discutida por Bauman (1999).

0 ponto central é que fazer parte desse circuito significa aceitar a hierarquização imposta pela academia anglo-saxã, que tende a nos colocar como subalternos. A presença de pessoas de outros países que não os centrais nesse circuito em geral está relacionada a estar empregado ou, então, ter relações fortes com as universidades centrais. É raro alguém localizado fora das universidades do "centro" fazer parte desse circuito. Vale frisar que nos próprios EUA e Reino Unido há uma quantidade expressiva de acadêmicos que estão fora desse jogo, muito embora estar empregado em uma universidade nesses países seja um ponto expressivo de vantagem. Vindo de um país como o Brasil, a menos que domine muito bem as práticas e jogue muito bem com as regras dessa academia anglo-saxã, você será considerado um derrotado.

Ibarra-Colado (2006) mostra como essa academia “global” possui um discurso altamente sedutor para vários agentes da América Latina. É como se fazer parte desse circuito "global" transformasse o acadêmico latino-americano em um ser "diferenciado" em relação aos seus colegas da região. Ter sucesso nessa academia "global" é, como diz o professor Bill Cooke, como ser um bom jogador de futebol americano. Você pode até treinar e se destacar nesse esporte que pouquíssimos jogam e conhecem bem, mas está longe de ser natural se você não for norte-americano ou não tiver sido formado lá.

Conforme destaquei no início deste artigo, há, no Brasil, um número crescente de periódicos no campo da Administração que publica seus artigos ou unicamente no idioma inglês ou privilegia artigos publicados em inglês. Boa parte deles trata-se de periódicos bem-conceituados na lista Qualis/CAPES da Administração, o que significa que há uma clara tendência de que, para publicar em um periódico nos extratos superiores do Qualis, o pesquisador terá que publicar em inglês. 0 que a experiência brasileira tem mostrado a respeito da publicação no Brasil de periódicos que privilegiam o inglês?

Se eu deixar de lado as perspectivas epistemológicas reflexivas que adoto em minhas pesquisas e pensar como alguém que defenderia a inserção do Brasil na academia "global” de Administração, e analisar a experiência dos periódicos nacionais em inglês, alguns aspectos sobressaem. Em primeiro lugar, basta 
uma breve pesquisa dos nomes e da filiação institucional das pessoas que publicam nesses periódicos para constatarmos que a imensa maioria dos autores dos textos publicados é brasileira. Ou seja, raros são os autores de fora do Brasil que utilizam os periódicos brasileiros em inglês para divulgar seus manuscritos. Percebemos, ainda, que os periódicos nacionais em inglês são raramente citados por autores de fora do Brasil.

Além disso, há uma tendência de que editores de periódicos no Brasil possuam restrita ou inexistente experiência de publicar em periódicos internacionais reconhecidos nas suas respectivas áreas. Parte das pessoas que possuem poder de decisão dos rumos da na área de Administração não possui formação ou interlocução internacional e ocupa as posições de poder muito mais por conta de questões políticas associadas ao seu poder nos jogos políticos do campo acadêmico da Administração do que pela demonstração de competência em fazer pesquisa e produzir conhecimento.

No momento em que um periódico passa a ser publicado em inglês, ele tem a vantagem potencial de ser acessado em todo o mundo "global". A desvantagem disso é que o artigo será imediatamente comparado com os demais artigos "globais". Tais artigos possuem um formato específico e uma maneira bastante peculiar de serem escritos e editados (Bell et al., 2016; Horn, 2017; Murphy \& Zhu, 2012). Os artigos “globais” envolvem caras revisões de idioma e uma quantidade de trabalho que não estamos acostumados a realizar para publicar textos no Brasil, onde é comum se fazer um artigo na véspera da conferência e rapidamente enviar para um periódico para ser publicado.

Para se publicar um artigo "global”, via de regra, o autor apresenta seu trabalho em conferências e, mais importante, em seminários pequenos onde estão outros acadêmicos "globais" que fazem comentários para que o autor desenvolva o texto. Isso significa que o texto submetido a um journal considerado de qualidade já passou pelo crivo de possíveis avaliadores. Já presenciei situações em que um autor apresenta seu artigo em um seminário com a presença de editores associados e ex-editores de periódicos extremamente reconhecidos. Os comentários fazem com que o autor melhore o seu texto dentro da lógica "global" de como deve ser um artigo. É ingenuidade imaginar que um autor faz um texto e submete para um periódico sem que ele tenha um grande número de comentários de pessoas que sabem o que é esperado nesse periódico. É necessário que ele discuta esse texto inúmeras vezes com pessoas do campo; assim, aos poucos, o seu texto vai ganhando o formato daquilo que é esperado no journal. É preciso estar dentro dos circuitos de conhecimento e poder da academia "global” em Administração. Há uma política da publicação "global” que raramente dominamos.
Dessa forma, por trás de artigos científicos, há uma prática institucionalizada de se fazer pesquisa e de se fazer ciência. Assim, os artigos que foram produzidos na lógica do publish or perish brasileiro ficam em clara desvantagem diante dos textos publicados no publish or perish anglo-saxão. Ao publicarmos nossos periódicos em inglês, entramos automaticamente em um sistema hierarquizado pelos anglo-saxões em que nós sempre seremos subalternos. Diante disso, a publicação de periódicos brasileiros em inglês acaba por expor as "fragilidades" da produção nacional em escala "global”. Em larga medida, é uma forma de expor a nossa "província" "globalmente", ou melhor, usando as palavras de Ortiz (2008), é uma forma de “provincianismo global”.

É típico, no provincianismo brasileiro, idolatrar o estrangeiro do mundo desenvolvido e querer realizar mimetismo de sua forma de atuação para parecer "desenvolvido". Sevcenko (1985), analisando o Rio de Janeiro da época do Barão de Rio Branco, relata que

Havia também uma prática espúria de controle e de ocultamento da dimensão negra da sociedade brasileira, sobretudo no contato com elementos estrangeiros. Essa era uma prática conduzida pelo Barão de Rio Branco no Itamarati. Entre as pessoas havia um cuidado para não sair ao sol. Na avenida, o grande lugar do desfile, os passeios só eram feitos do lado da sombra: de manhã de um lado, à tarde no outro. Ninguém tomava banho de mar. E um hábito entre os mais jovens, entre os nubentes, era o de tomar um copo de vinagre em dejejum para provocar o embranquecimento da pele, resultando numa palidez meio esverdeada que era tida como de alto bom gosto (p. 49).

Há, ainda, uma questão de ordem prática que os pesquisadores precisam levar em conta. Se os periódicos nacionais em inglês ou que estão migrando para o inglês são raramente referenciados na audiência "global", quase nunca fazem parte dos rankings de periódicos "globais" e raramente são citados fora do Brasil, há poucos motivos para um pesquisador que possui um artigo que ele considera "bom" em inglês enviar para um periódico brasileiro editado em inglês. Publicar nesses periódicos não auxiliará a sua produção científica a ser "global” ou você a participar de um debate acadêmico "global”.

Além disso, a grande maioria dos periódicos brasileiros faz com que os autores tenham que arcar com o custo das traduções 
dos textos uma vez aceitos, gerando um custo alto para um periódico que está em inglês, mas não é “global”. Eu mesmo já tive a experiência de ter um artigo aprovado em português e ter de arcar com os custos de tradução, sem ter sido anteriormente avisado a respeito disso. Se eu quisesse que o texto fosse publicado em inglês, teria enviado para um periódico internacional de destaque, afinal publicar em um periódico não reconhecido "globalmente" pode depor contra o autor do texto, pois esse tipo de julgamento é feito constantemente. Se há pesquisadores que querem fazer parte do circuito "global" da ciência, há inúmeros periódicos disponíveis para que eles publiquem seus estudos, e esse é o único caminho a ser percorrido para quem tem esse desejo. Não precisamos transformar os nossos periódicos em mímicas (Bhabha, 1994) de periódicos “globais”.

Se os periódicos brasileiros querem ser "globais", eles precisam mudar radicalmente a sua forma de atuação. Os chineses estão percorrendo esse caminho. Desde o ano de 2005, a The International Association for Chinese Management Research publica o periódico Management and Organization Review (MOR). Hoje, o periódico tem um fator de impacto JCR de 2,738 (2015) e está entre os 35 periódicos com maior fator de impacto JCR da área. O primeiro número do periódico contou com um texto de James March. O periódico foi editado pela Willy e hoje é editado pela Cambridge University Press. 0 ex-editor e o atual editor do MOR possuem vasta experiência em publicar em periódicos “globais", assim como muitos dos autores de artigos publicados no MOR. Há, ainda, uma presença maciça de chineses fazendo seus PhD em universidades de ponta nos EUA e na Europa, e investimento do governo chinês e de empresas do país em tais universidades. 0 exemplo chinês mostra que, para se fazer parte do mundo dos periódicos "globais" e desafiar a presença hegemônica dos anglo-saxões, é preciso muito mais do que boa intenção e boa vontade. É necessário investimento de longo prazo, lidando com as regras do jogo vigentes. Artigos e periódicos estão imersos em um contexto social, econômico e geopolítico. Desconsiderar isso até soa ingênuo. Diante do exposto, se publicar periódicos brasileiros em inglês é uma tentativa de transformar a nossa academia em "global”, não é isso que acontecerá, como, aliás, já estamos constatando desde que periódicos em inglês começaram a ser publicados no Brasil. Precisamos ir além do paroquialismo global que nos faz construir simulacros de periódicos "globais".

Há um outro ponto relevante a ser considerado. Para quem realizamos a nossa pesquisa? Qual o objetivo de realizarmos o nosso trabalho acadêmico? Para que servem os nossos programas de pós-graduação stricto sensu? A resposta para essas perguntas, eu entendo, deve levar em conta o lugar de onde estamos escrevendo. O Brasil é um país de dimensões continentais com um número considerável de problemas sociais, políticos e econômicos. Grande parte dos programas de pós-graduação do Brasil está imerso em uma lógica local que possui raízes que precisam ser levadas em conta. Grande parte da atividade principal dos que se formam doutores no Brasil é ministrar aulas e fazer gestão acadêmica em suas universidades. No que ajuda o Brasil e o local onde esses programas de mestrado e doutorado estão inseridos publicar em periódicos brasileiros em inglês? Não seria mais sensato e ponderado fazer com que esse grande contingente de alunos de mestrado e doutorado estivesse pesquisando assuntos que dizem respeito a suas realidades locais e tentando utilizar a ciência para transformar esses mundos? Faz sentido que todos os programas de pósgraduação do Brasil sejam avaliados com as mesmas métricas, as mesmas regras? Faz sentido essa mímica do publish or perish anglo-saxão que, no final, não forma bons professores em sala de aula para o mercado brasileiro? Eu considero que não. É urgente que a nossa pós-graduação e nossa produção científica se voltem para as realidades e problemas locais, algo que também não acontece no atual sistema de publish or perish brasileiro.

É preciso que utilizemos os periódicos nacionais em português para combatermos o colonialismo epistêmico que faz com que deixemos de considerar quem somos, para quem fazemos pesquisa e a realidade onde estamos em nome de um saber universal que, no final, sempre nos transforma em subalternos (Ibarra-Colado, 2006). Não podemos meramente reproduzir de maneira ingênua as mesmas lógicas anglo-saxãs de avaliação de produção científica.

O Brasil tem dimensões que lhe permitem criar uma lógica de produção de conhecimento que supere e vá além do publish or perish vigente atualmente tanto no Brasil quanto no exterior. Precisamos desenvolver uma lógica que não siga a englishzation, que produz identidades reguladas pela lógica do Império "global" (Boussebaa \& Brown, 2017). O modelo do publish or perish não traz significado para a vida de pesquisadores tanto no Brasil quando no exterior. Publicar em português pode servir como uma forma de resistir a essa lógica. Se queremos ser "globais", podemos utilizar os nossos periódicos para articular uma posição acadêmica do Sul, aceitando artigos em espanhol e francês, por exemplo, como têm feito alguns periódicos do campo no Brasil. Podemos nos articular com outros espaços que têm buscando formar resistências (Chanlat, 2014).

É urgente utilizar a força das agências que regulam a produção em conhecimento em Administração, como Associação Nacional de Pós Graduação e Pesquisa em Administração (ANPAD), CAPES e CNPq, e também os nossos periódicos, para criarmos 
um espaço acadêmico próprio que lide com a nossa realidade e com os nossos problemas e que, acima de tudo, sirva como espaço de resistência ao modelo que está aí e que nos constrói, sempre, como inferiores. Mas precisamos também mudar a lógica que impera hoje no campo da Administração no Brasil, que nos transforma em uma cópia malfeita e muito mal acabada da academia anglo-saxã. E o caminho está em termos nossos periódicos em português, aceitando outros idiomas do Sul, e não obrigando nossos pesquisadores a pagarem altos custos para fazer parte de uma academia que deveria ser sua. Para isso, nossos periódicos precisam falar português (Rosa \& Alves, 2011).

\section{REFERÊNCIAS}

Alcadipani, R. (2011). Resistir ao produtivismo: Uma ode à perturbação acadêmica. Cadernos EBAPE, 9(4), 1174-1178. doi:10.1590/S167939512011000400015

Altbach, P. G. (2007). The imperial tongue: English as the dominating academic language. Economic and Political Weekly, 42(36), 36083611.

Bauman, Z. (1999). Globalização: As conseqüências humanas. Rio de Janeiro, RJ: Jorge Zahar Editor.

Bell, E., Kothiyal, N., \& Willmott, H. (2016). Methodology-as-technique and the meaning of rigour in globalized management research. Artigo em preparação.

Bertero, C., \& Caldas, M. (2005). Produção científica em Administração no Brasil: $O$ estado da arte. São Paulo, SP: Atlas.

Bertero, C., Caldas, M., \& Wood, T. (1999). Produção científica em Administração de empresas: Provocações, insinuações e contribuições para um debate local. RAC, 3(1), 147-178. doi:10.1590/S141565551999000100009

Bhabha, H. (1994). The location of culture. London, UK: Routledge.

Boussebaa, M., \& Brown, A. D. (2017). Englishization, identity regulation and imperialism. Organization Studies, 38(1), 7-29. doi:10.1177/0170840616655494

Bristow, A., Robinson, S., \& Ratle, O. (2017). Being an early-career CMS academic in the context of insecurity and 'excellence': The dialectics of resistance and compliance. Artigo em preparação.
Chanlat, J. F. (2014). Language and thinking in organization studies: The visibility of French OS production in the Anglo-Saxon OS field. International Journal of Organization Analysis, 22(4), 504-533. doi:10.1108/IJOA-09-2013-0708

Davies, G. (2015). What organization theory is for? Administrative Science Quarterly, 6o(2): 367-371. doi:10.1177/0001839215585725

Godoi, C., \& Xavier, W. (2012). Produtivismo e suas anomalias. Cadernos EBAPE, 10(2), 456-465. doi:10.1177/0001839215585725

Horn, S. (2017). Non-English nativeness as stigma in academic settings. Artigo em preparação.

Ibarra-Colado, E. (2006). Organization studies and epistemic coloniality in Latin America: Thinking otherness from the margins. Organization, 13(4), 463-488. doi:10.1177/1350508406065851

Latour, B., \& Wolgar, S. (1986). Vida de laboratório. Rio de Janeiro, RJ: Relume Dumara.

Machado, A., \& Biachetti, L. (2011). (Des)Fetichização do produtivismo acadêmico: Desafios para o trabalhador-pesquisador. RAE-Revista de Administração de Empresas, 51(3), 244-254. doi:10.1590/So03475902011000300005

Murphy, J., \& Zhu, J. (2012). Neo-colonialism in the academy? Anglo-American domination in management journals. Organization, 19(6), 915-927. doi:10.1177/1350508412453097

Ortiz, R. (2008). A diversidade dos sotaques: $O$ inglês e as ciências sociais. São Paulo, SP: Brasiliense.

Pegino, P. (2014). As relações acadêmicas de produção na pós-graduação em Administração no Brasil (Tese de doutorado, FGV-EAESP).

Rosa, A. R., \& Alves, M. A. (2011). Pode o conhecimento em gestão e organização falar português? RAE-Revista de Administração de Empresas, 51(3), 255-264. doi:10.1590/So034-75902011000300006

Sevcenko, N. (1985). As muralhas invisíveis da Babilônia moderna. Óculum Revista da Arquitetura, 1, 12-22.

SCI\&ORG - Ciência e Organizações. (2017, 2 Fevereiro). Confira o último Qualis (2015) dos periódicos nacionais com ênfase em Adminis tração [Post da web]. Recuperado de https://sciandorg.wordpress. $\mathrm{com} / 2017 / 02 / 02 /$ confira-o-ultimo-qualis-dos-periodicos-com-enfase-em-administracao/

Wilson, L. (1942). The academic man: A study in the sociology of a profession. London, UK: Transaction Publishers. 